\title{
Influence of Process Parameters on Physical and Mechanical Parameters of Friction Surfaced Deposits on Low Carbon Steel
}

\author{
S. Ravi Sekhar*l, D. Govardhan'², R. Karthikeyan ${ }^{3}$, Ram Subbaiah $^{4}$
}

${ }^{1}$ Department of Mechanical Engineering, Gokaraju Rangaraju Institute of Engineering and Technology, India. ${ }^{2}$ Department of Mechanical Engineering, Institute of Aeronautical Engineering, Hyderabad, India.

${ }^{3}$ Department of Mechanical Engineering, Gokaraju Rangaraju Institute of Engineering and Technology, India.

${ }^{4}$ Department of Mechanical Engineering, Gokaraju Rangaraju Institute of Engineering and Technology, India.

\begin{abstract}
Friction surfacing is the innovative technique employed for the reformation of a metal surface. Frictional heat produced between two interaction surfaces is utilized to deposit one metal above the other professionally. In this process, the quantity heat needed for depositing is essentially be influenced by on choice of process constraints such as friction force, revolving speediness of mechtrode, table speediness and reside duration. Stainless steel was selected for friction surfacing on mild steel in this experiment, the number of experiments were decided based on factorial design. Investigational task of friction surfacing was executed and the responses were quantified from the deposits which were accepted after thorough inspection. Through regression equations the impact of procedure features on each response was determined.
\end{abstract}

\section{Introduction}

Friction surfacing is a unique type of friction joining practice which is a solid phase welding procedure through which one metal layered over the other effectively. In this method, the portions are exposed to move relative to another under frictional force so that the frictional heat energy produced at the interface faying faces. The generated heat is employed to seem like or divergent metals.

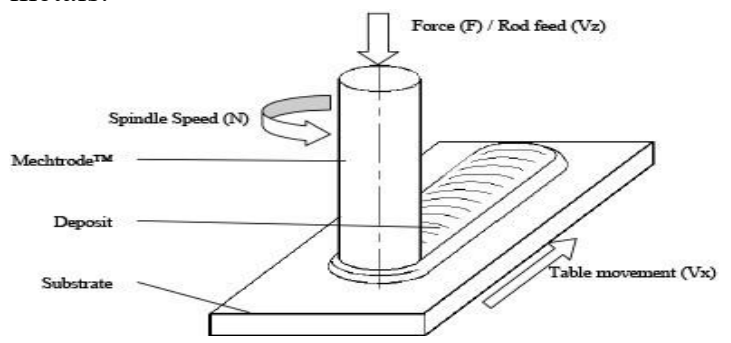

Fig. 1 Explain the principle involved id deposition of stainless over low carbon steel

This method is simply governable, repeatable, and consistent and is a modest machine tool expertise, having equivalent advantages like conventional joining procedures. It is observed that no slag inclusions, pores and reductions on the deposit which are commonly encountered in conventional welding procedures. This procedure itself is eco-friendly, hence it is treated as green manufacturing technology. The Heat affected zone is comparatively very small. Henceforth further heat treatment process are not usually necessary for internal stresses induced.[1-4]

In this procedure, the mechtrode is made in the form of circular shaft and revolved at a pre- determined angular speed. It is moved with axial load towards base metal where the frictional heat is generated near the contact surfaces. When forging temperature is obtained, the base metal moves with a pre- determine velocity and certain percentage of plastic state of metal produced at contact surface is deposited on base metal with sufficient strength. The torque-time factors will play vital role in production of heat energy at the interface. It is observed that the physical characteristics of the deposit are influenced with the friction force, revolving speediness of mechtrode besides speediness of base metal moved and therefore these are termed procedure constraints. Diagram1, demonstrates the procedure and process parameters implicated in friction surfacing.

This method is employed to weld an extensive range of alike and divergent metals [11-13]. Aluminium and brass 
metals both can be used for joining due to high thermal conductivity of either metal [14]. In this investigation, stainless steel is used as deposit material on low carbon steel.

\section{Experimentation}

In present investigation, stainless steel material was chosen as the deposit material over low carbon steel. The values of the process constraints depends on characterization of weld as i) forging strength and diameter of mechtrode ii) frictional force and iii physical and mechanical characteristics of mechtrode include base metal. Moreover, the ranges of process values were also influenced by the metallurgical properties of inter-metallic composites produced as a result of formation of mechtrode materials and base metal.

\subsection{Selection of Friction Pressure}

The heat produced is due to the friction force and revolving speediness of consumable, if the friction force is too high, there is chance of twisting of consumable rod, hence forging strength is important to fix the upper level of the friction pressure

\subsection{Mechtrode's revolving speed}

The temperature near the intersection of the mechtrode and base metal is nearer to the melting point of the mechtrode for getting desirable bond and good covering integrity. Since the upper limit of the friction force is subject to the forging strength of selected materials and the corresponding lesser value on revolving speediness is determined.

\subsection{Selection of welding speed}

Welding speediness effects on layer thickness than the layer width. It was found that $0.04 \%$ stainless steel which is heated malleable state was set down on low carbon steel during friction surfacing. The breadth of the coat is varying with process parameters, but average value is nearer to 0.75 times the span of stainless steel introduced. If the welding speed is high, height of the deposit is decreased and vice versa.

\subsection{Dwell}

Dwell time is selected about 5 seconds for stainless steel deposition above low carbon steel The parameters and levels of every parameters are represented in table 1 .

Table1: Parameters used for deposit of stainless steel on low carbon steel

\begin{tabular}{|c|c|c|c|c|c|}
\hline \multirow[b]{2}{*}{ S. No } & \multirow[b]{2}{*}{ Factors } & \multirow{2}{*}{$\begin{array}{c}\text { Notati } \\
\text { on }\end{array}$} & \multirow[b]{2}{*}{ Unit } & \multicolumn{2}{|c|}{ Level } \\
\hline & & & & $\begin{array}{c}\text { Minimum } \\
(-1)\end{array}$ & $\begin{array}{c}\text { Maximu } \\
\mathbf{m}(+1)\end{array}$ \\
\hline 1 & $\begin{array}{c}\text { Friction } \\
\text { Force/Pressure }\end{array}$ & $\mathrm{X} 1$ & $\mathrm{MPa}$ & 26 & 49 \\
\hline 2 & $\begin{array}{c}\text { Revolving } \\
\text { speediness of the } \\
\text { Consumable }\end{array}$ & $\mathrm{X} 2$ & rpm & 1400 & 2500 \\
\hline 3 & Table speediness & $\mathrm{X} 3$ & $\underset{\mathrm{n}}{\mathrm{mm} / \mathrm{mi}}$ & 78 & 190 \\
\hline
\end{tabular}

The statistical procedure methodology the 23 factorial designs i.e. with three factors and two levels for each is followed for experimental work. The design matrix showing 8 combinations for stainless steel deposition is shown in Table $2.15 \mathrm{~mm}$ diameter of 304 stainless steel rods were made of $290 \mathrm{~mm}$ length pieces, which are used as mechtrodes to deposit over the base metal of low carbon steel by friction surfacing. The process constraints according to combination were set upon the computer for performing the experiments. With Reside interval of 5 seconds was maintained for deposition of stainless steel over the base metal. The layers of the deposited materials on the substrate is also shown in Table no 2 and figure no 2 shows the machine which was employed to execute the experimental work of friction surfacing.

Table 2: The deposited materials

\begin{tabular}{|c|c|c|c|c|}
\hline \multirow{2}{*}{$\begin{array}{c}\text { Depos } \\
\text { its } \\
\text { numb } \\
\text { er }\end{array}$} & $\begin{array}{c}\text { Axial } \\
\text { load } \\
\text { (MPa) }\end{array}$ & $\begin{array}{c}\text { Revolvi } \\
\text { ng } \\
\text { speedin } \\
\text { ess }\end{array}$ & $\begin{array}{c}\text { Table } \\
\text { speedine } \\
\text { ss }\end{array}$ & Deposition of SS on LCS \\
\hline 1 & 25 & 1350 & 75 & (2) \\
\hline 2 & 48 & 1350 & 75 & \\
\hline 3 & 25 & 2400 & 75 & \multirow{2}{*}{} \\
\hline 4 & 48 & 2400 & 75 & \\
\hline 5 & 25 & 1350 & 180 & \\
\hline 6 & 48 & 1350 & 180 & \\
\hline 7 & 25 & 2400 & 180 & \\
\hline 8 & 48 & 2400 & 100 & \\
\hline
\end{tabular}

\section{Results and Discussions}

After completion of the experimentation the deposits were examined visually for the physical features and defectiveness happened before processing further tests. They were conducted on shop floor to identify the physical responses of the welded Layers like breadth, stature and surface roughness also the solidity of deposits such as shear 
and tensile strength. The standard procedure ASTM 264 was followed to estimate the tensile strength. The specimens used for shear and ram tensile strength are shown in table 3 . The calculated values for mechanical strength of the stainless steel deposits tabulated in table 4 .

Table 3: The specimens of shear and tensile strength test

\begin{tabular}{|c|c|c|}
\hline $\begin{array}{c}\text { Stainless steel } \\
\text { deposit }\end{array}$ & Deposit & \\
\hline & $\begin{array}{c}\text { Specimen } \\
\text { before test }\end{array}$ & \\
\hline & $\begin{array}{c}\text { Specimen } \\
\text { after test }\end{array}$ & Shear strength test \\
\hline 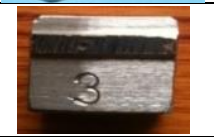 & $\begin{array}{l}\text { Specimen } \\
\text { before test }\end{array}$ & \\
\hline & $\begin{array}{c}\text { Specimen } \\
\text { after test }\end{array}$ & Tensile strength test \\
\hline
\end{tabular}

Table 4: Responses of stainless steel deposit over low carbon steel

\begin{tabular}{|c|c|c|c|c|c|}
\hline $\begin{array}{c}\text { Expt. } \\
\text { No. }\end{array}$ & $\begin{array}{c}\text { Width } \\
(\mathbf{m m})\end{array}$ & $\begin{array}{c}\text { Height } \\
(\mathbf{m m})\end{array}$ & $\begin{array}{c}\text { Surface } \\
\text { roughness } \\
(\boldsymbol{\mu m})\end{array}$ & $\begin{array}{c}\text { Shear } \\
\text { Strength } \\
(\mathbf{M P a})\end{array}$ & $\begin{array}{c}\text { Tensile } \\
\text { Strengt } \\
\mathbf{h}(\mathbf{M P a})\end{array}$ \\
\hline 1 & 10.9 & 1.4 & 6.82 & 72.5 & 297 \\
\hline 2 & 12.45 & 2.6 & 2.63 & 85 & 326 \\
\hline 3 & 11.52 & 1.5 & 6.25 & 156 & 456 \\
\hline 4 & 14.15 & 1.6 & 1.94 & 155 & 448 \\
\hline 5 & 10.44 & 1.1 & 6.10 & 172 & 518 \\
\hline 6 & 12.47 & 1.2 & 7.83 & 162 & 484 \\
\hline 7 & 10.76 & 0.9 & 6.65 & 350 & 586 \\
\hline 8 & 13.25 & 1.5 & 9.68 & 150 & 360 \\
\hline
\end{tabular}

\subsection{Analysis of deposits by regression equations}

The responses of the stainless steel deposits on low carbon steel obtained by means of eight combinations were analyzed in Minitab software. The regression equations the responses of stainless steel deposit above low carbon steel is summarized in Table 5. As the value of the each response is not same with all eight experiments. The mechanical properties like tensile strength increases with the three factor interactions of axial load, revolving and transverse speediness .But it decreases with the welding speed, the collective influence of friction force and revolving speediness, one more interaction of revolving speediness and table speediness.

Table 5: Regression equations for the responses of stainless steel deposit over low carbon steel

\begin{tabular}{|c|c|c|}
\hline S.No & Response & $\begin{array}{l}\text { Regression Equations (Eliminated } \\
\text { least significant terms) }\end{array}$ \\
\hline 1 & Width & $\begin{array}{l}y=11.9925+1.0875 \times 1 \quad+0.4275 \times 2- \\
0.2625 X 3+0.1925 \times 1 X 2\end{array}$ \\
\hline 2 & Height & 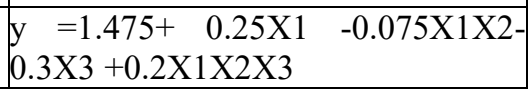 \\
\hline 3 & \begin{tabular}{|l} 
Surface \\
Roughnes \\
s
\end{tabular} & $\begin{array}{l}\mathrm{y}=5.9875-0.4675 \mathrm{X} 1 \quad+1.5775 \mathrm{X} 3 \\
+1.6575 \mathrm{X} 1 \mathrm{X} 3+0.4575 \mathrm{X} 2 \mathrm{X} 3\end{array}$ \\
\hline 4 & $\begin{array}{l}\text { Tensile } \\
\text { strength }\end{array}$ & $\begin{array}{lrr}y & =437.625 & -31.875 X 1 X 2- \\
19.125 X 3-88.875 & X 2 X 3 \\
+52.375 X 1 X 2 X 3 & \\
\end{array}$ \\
\hline 5 & $\begin{array}{l}\text { Shear } \\
\text { strength }\end{array}$ & $\begin{array}{l}y \quad=162.8125-24.8125 \mathrm{X} 1 \\
39.9375 \mathrm{X} 2- \\
25.4375 \mathrm{X} 1 \mathrm{X} 2+45.6875 \mathrm{X} 3- \\
27.6875 \mathrm{X} 1 \mathrm{X} 3\end{array}$ \\
\hline
\end{tabular}

\section{Conclusions}

In this project, stainless steel (304) as mechtrode plus low carbon steel introduced as consumable and base metals respectively.23 factorial design was used conducting experimental work. The values of each experiment, it was representing that parameters are played crucial role on each response. The influence of process parameters on the each response are determined by establishing, the regression equation. Finally, from the investigation it is found that at least one process parameter is proportional to each response of stature, shear strength physical properties as width, stature and mechanical properties like surface coarseness and shear strength of stainless steel deposit over low carbon steel. But none of the parameter was directly proportional to the response of tensile strength. The shear strength is increases with revolving speed and transverse speediness and is inversely relative to friction force and interactions of friction force, revolving speediness, and collective influence of three factors such as axial load, revolving and transverse speediness.

\section{SALUTATIONS}

The authors would like to thanks to the Director, Defence Metallurgical Research Laboratory, Hyderabad, India and Dr. G. Madhusudan Reddy, director of its Metal Joining Group, for their continued encouragement and technical support given for doing experimental work and investigating the results. We also thank to the management, director and principal of Gokaraju Rangaraju Institute of Engineering and Technology and Institute of Aeronautical Engineering, Dundigal, Hyderabad for their encouragement and provided that amenities for testing the deposit of this research work. 


\section{References}

1. Wayne Thomas, Edward D Nicholas TWI England, 1990 U.S Patent No.4, 959, 241.

2. K.G.K. Murti, K.AshokKumar and A.N.Dhawan WRI Journal Vol 15 No 3. P85-93

3. Margam Chadrashekaran and Sukumar Jana 5 Materials Processing Technology 72 (1997) 446452.

4. A.W.Batchlor, S. Jana, C .P. Koh and C .S .Tan ing5 materials processing technology- 57 (1996) 172-181

5. M. Chandrasekaran, A.W.Batchelor, S.Jana, S.Mater, Sci. 32 (1997) 6055

6. Horoshi. TOKISUE, Kaazuyoshi KATOH, Toshikatsu ASHAINA and Toshio SHIYAMA from Industrial Technology Nihon University Nov 78, 2005.
7. Margam Chadrashekaran, A.W. Batchlor and Sukumar Jana, Journal of Materials Processing Technology 72 (1997) 446-452.

8. Suresh Kumar T, Sankar V, 2011 IEEE India Conference, INDICON, 2011

9. G.Madhusudhan Mohandas "Surface Engineering 2009, V 000, 1-8.

10. M.Liu, Z.D.Zou, Y.H.Zhang, S.Y.Qu, X.H.Wang, Science Direct: Surface and Coating technology202 (2008), pp 1889-1894

11. K.G.K. Murti and S. Surdaresan, Metal Construction 156 (1983), pp.331-335.

12. Bankupalli, P.T., Srikanth Babu, V., Suresh Kumar. T, International Journal of Applied Engineering Research, 10(16), 2015.

13. G.Madhusudhan Reddy, K.SrinivasaRao and T., Vol 47, No 11/12; 2003

14. Nicholas ED, Reddy, K.SrinivasaRao and Mohandas Surface Engineering 2008 V 000, 1-6. 